\title{
Aster tataricus Linn., Suppresses Hepatic Stellate Cell Activation and Protects Against Thioacetamide-induced Liver Fibrosis in Rats
}

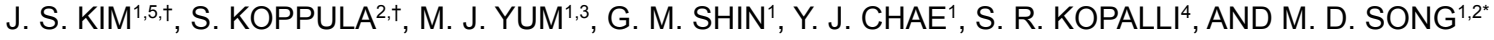

${ }^{1}$ Research Institute and College of Biomedical \& Health Science (RIBHS), Konkuk University, 268 Chungwon-daero, Chungju-si, Chungbuk, 27478, Korea, Republic of Korea, ${ }^{2}$ Department of Biotechnology, College of Biomedical and Health Sciences, Konkuk University, 268 Chungwon-daero, Chungju-si, Chungbuk, 27478, Republic of Korea, ${ }^{3} 1014$ Gwanggyo Ace Tower1, 17, Daehak 4-ro, Yeongtong-gu, Suwon-si, Gyeonggi-do, 16226, Republic of Korea, ${ }^{4}$ Department of Bioscience and Biotechnology, Sejong University, Gwangjin-gu, Seoul 05006. Republic of Korea, ${ }^{5}$ Department of internal Medicine, college of Medicine, The Catholic University of Korea, Seoul, Republic of Korea
\end{abstract}

\section{Kim et al.: Antihepatofibrotic Effect of Aster tataricus}

\begin{abstract}
Aster tataricus Linn., (Asteraceae), an oriental and nutrient-potential herb is used in Asian countries for various health benefits. The present study focused on the protective effects of Aster tataricus against liver fibrosis in cellular and an experimental rat model. Cell cytotoxicity, cell cycle and apoptosis functions were analyzed using hepatic stellate cell lines following MTT assay, flow cytometry, and Annexin V-FITC/PI staining methods. For in vivo evaluation, thioacetamide-induced hepatofibrosis rat model was established. Sprague Dawley rats were divided into 5 groups of 10 each (control, thioacetamide, thioacetamide with Aster tataricus extract 100 and $500 \mathrm{mg} / \mathrm{kg}$ and silymarin $50 \mathrm{mg} / \mathrm{kg}$ groups, respectively). Fibrosis was induced by thioacetamide treatment $(200 \mathrm{mg} / \mathrm{kg}$, ip) 3 times per week for 13 weeks except for the control group. Aster tataricus extract (100 and $500 \mathrm{mg} / \mathrm{kg})$, and silymarin was administrated orally to each group 6 times a week from week 7 to 13 and various fibrosis-related parameters were estimated using real-time polymerase chain reaction using TRIzol Plus RNA purification Kit and a spectrophotometer. Results indicated that hepatic stellate cells treated with Aster tataricus extract $(0.5 \mathrm{mg} / \mathrm{ml})$ and silymarin $(0.05 \mathrm{mg} / \mathrm{ml})$ significantly $(\mathrm{p}<0.05)$ induced apoptosis $(19.04$ and $24.82 \%$, respectively) compared to the control group $(9.78 \%)$. Moreover, rat primary hepatic stellate cells showed morphological changes and degradation of collagen and fibronectin when treated with $0.5 \mathrm{mg} / \mathrm{kg}$ of Aster tataricus extract. In vivo evaluation Aster tataricus extract at concentrations of 100 and $500 \mathrm{mg} / \mathrm{mlattenuated}$ the increased serum levels of alanine transaminase, aspartate transaminase and hydroxyproline and restored the decreased glutathione levels significantly in thioacetamide induced fibrotic rats $(p<0.05)$. The altered histopathology in thioacetamide-induced liver tissues and changes in fibrosis-related gene expression (TGF- $\beta$, $\alpha-S M A$ and Col1a1) were also restored by Aster tataricus extract treatment. In conclusion, Aster tataricus can be developed as a potential therapeutic agent in the treatment of liver fibrosis.
\end{abstract}

Key words: Liver fibrosis, thioacetamide, apoptosis, hepatic stellate cells, hydroxyproline

Liver fibrosis, one of the critical disorders in the world population results from chronic hepatic injury, autoimmune hepatitis, hepatitis $\mathrm{C}$ infection, alcoholic and non-alcoholic fatty liver and non-alcoholic steatohepatitis with sustained inflammation, formation of scar, altered tissue architecture and organ failure ${ }^{[1]}$. Deposition of extra cellular matrix (ECM) proteins, a major source of fibrillary and non-fibrillar matrix by hepatic stellate cells (HSCs) activation is considered as one of the important characteristic featuresin the

*Address for correspondence

E-mail: minds@kku.ac.kr

${ }^{\dagger}$ Contributed equally to this work pathogenesis of liver fibrosis ${ }^{[1-3]}$. HSCs are normally quiescent and possess low proliferation rate, but at conditions of hepatocyte damage or injury they get activated with increased proliferation rate further transforming into myofibroblast-like phenotypic cells.

This is an open access article distributed under the terms of the Creative Commons Attribution-NonCommercial-ShareAlike 3.0 License, which allows others to remix, tweak, and build upon the work non-commercially, as long as the author is credited and the new creations are licensed under the identical terms

Accepted 02 December 2019

Revised 18 September 2019

Received 28 July 2019

Indian J Pharm Sci 2020;82(1):104-113 
This condition causes severe damage to the normal architecture of the liver and therefore considered as an important stage during progressive liver disease $\mathrm{e}^{[4-8]}$. Inhibiting ECM secretion by activated HSCs and targeting HSCs apoptotic pathways, which are involved in the pathogenesis of liver fibrosis has great significance in ameliorating chronic liver diseases ${ }^{[9]}$. Several studies on thioacetamide (TAA) in experimental animals revealed similar mechanism of liver fibrogenesis both metabolic and histological when compared with the fibrotic livers of humans including virus-induced cirrhosis ${ }^{[10,11]}$. Therefore, TAAinduced liver fibrosis in rodents could be a classical model to evaluate therapeutic efficacy of various agents for studying liver damage and liver fibrosis ${ }^{[11]}$. Use of natural products derived from plants in aiding liver capacity and preventing liver damage such as Ampelopsis brevipedunculata, Orostachys japonicus, Artemisia, Chrysanthemum, Plantago seed, Gardenia jasminoides and Paeonialactiflora have been practiced in Asian countries since centuries ${ }^{[12]}$. Many factors contribute to herbal medicine's appeal and supporters of traditional herbal medicine claim that herbs may both treat and prevent liver fibrosis and also act as potential nutrients in strengthening liver functions ${ }^{[13]}$. Aster tataricus Linn., from the family Asteraceae, is distributed widely in Asian countries and has been used as a common traditional medicine for the relief of coughs and as an expectorant. Scientific studies revealed that $A$. tataricus possessed diuretic, antitumor, antibacterial, antivirus, antiulcer activities and related hepatic microsomal biotransformation ${ }^{[14,15]}$. The major constituents of $A$. tataricus are terpenoids, sterols, flavonoids, polysaccharides and cylclopeptides ${ }^{[16-17]}$. Recently, the roots and rhizomes of $A$. tataricus have been reported to inhibit HBV DNA replications and the human gastric carcinoma cell growth indicating that it could act as a natural anticancer agent ${ }^{[16,17]}$. A. tataricus was also reported to have antioxidant activity and reduce the levels of alanine aminotransferase (ALS), aspartate aminotransferase (AST) and alkaline phosphatase (ALP) in hepatotoxic effect induced by Fr- $2^{[18,19]}$. More recently, potential inhibitors were isolated from Aster tataricuswhich exhibited antiinflammatory effects bypreventing the downstream activation of the mitogen-activated protein kinase signaling pathway ${ }^{[20,21]}$. A. tataricus was found to protect retinal damage in diabetic rats due to the antioxidant and antiinflammatory effects $^{[22]}$ and attenuated neuroinflammation by decreasing the oxidative stress and inhibiting the cytokine production in LPS-stimulated rat astrocytoma cell line (C6) and THP-1 cells ${ }^{[23]}$. Further, A. tataricus extract was also reported to possess antiinflammatory and anticancer activity in LPS-induced acute lung injury model and by effectively attenuating the growth of SCC-9 cancer cells by virtue of its cytotoxic and anticlonogenic activity $^{[24,25]}$. Owing to its immense pharmacological properties, in the present study the antihepatofibrotic effects of A. tataricus extract was investigated in HSCs and in a TAA-induced liver fibrosis rat model.

\section{MATERIALS AND METHODS}

Hydroxyproline, TAA, glutathione (GSH), chloramine-T, 5,5-dithiobis-2-nitrobenzoic acid (DTNB), nicotinamide adenine dinucleotide phosphate ( $\beta$-NADPH), $\quad \mathrm{p}$-dimethylaminobenzaldehyde, 1, 1,3,3tetraethoxypropane (TEP) and 3-(4,5-demethylthiazol2yl)-2,5-diphenyl-2H-tetrazolium bromide (MTT) were purchased from Sigma (St. Louis, Missouri, USA). Annexin V-Fluorescein isothiocyanate (FITC) and propidium iodide (PI) Apoptosis Detection Kit I and GOT-GPT assay kits were obtained from BD Biosciences (San Jose, CA, USA). Perchloric acid was purchased from GFS chemical Co, (Columbus, Ohio, USA). All other chemicals used were of highest quality commercially available.

\section{Plant collection and extraction:}

The root of A. tataricus collected during June-July, 2018, was purchased from Ichanbang Medical Herb Co., Jecheon, Chungcheongbuk-do, South Korea. For extraction, Soxhlet extraction technique was used as described previously ${ }^{[21]}$. Briefly, finely powdered A. tataricus $(1 \mathrm{~kg})$ was extracted with 51 of ethanol (95\%) for $3 \mathrm{~d}$ and the collected extract was concentrated under reduced pressure, lyophilized and stored in a refrigerator at $4^{\circ}$. The final yield of $A$. tataricus extract (ATE) was $12.5 \%(\mathrm{w} / \mathrm{w})$. ATE stock for use in each experiment was prepared by dissolving ATE in $10 \%$ dimethyl sulfoxide (DMSO, Junsei Chemical Co., Ltd., Tokyo, Japan) and then filtered through a $0.22 \mu \mathrm{M}$ syringe filter. The final concentration of DMSO used for the study was not more than $0.1 \%$.

\section{Cell lines and culture:}

An immortalized rat hepatic stellate cell line (HSC-T6) was obtained from Korean Hospital of Daejeon University, Daejeon, South Korea. Chang liver cell lines was purchased from American Type Culture Collection (Manassas, VA, USA). HSC-T6 cells were cultured in Dulbecco's modified Eagle media (DMEM, 
Invitrogen, Carlsbad, CA, USA) supplemented with $5 \%$ fetal bovine serum (FBS, Invitrogen, Carlsbad, CA, USA) and $1 \%$ antibiotic-antimycotic (Invitrogen, Carlsbad, CA, USA) in a humidified atmosphere of 5\% $\mathrm{CO} 2$ at $37^{\circ}$. The Chang liver cell line was used as a normal human cell line derived from normal liver tissue and cultured as described previously ${ }^{[26]}$. HSC-T6 cells were activated by serum starvation before treatment with ATE. The protocol for primary HSCs isolation and culture was performed as described previously ${ }^{[27,28]}$.

\section{Cell viability assay:}

The effect of ATE on overall cell viability was evaluated using MTT assay and the results were measured on an ELISA reader at $540 \mathrm{nM}$ as described previously ${ }^{[26]}$. Briefly, the cells were treated with ATE $(24 \mathrm{~h})$ at various concentrations $(0,0.1,0.5,1.0 \mathrm{mg} / \mathrm{ml})$ and were incubated with $0.5 \mathrm{mg} / \mathrm{ml}$ MTT for $3 \mathrm{~h}$, and then the reaction was interrupted by addition of DMSO. The viability of control cells were used as the control values at $100 \%$.

\section{Cell cycle and apoptosis analysis:}

Cell cycle analysis in HSC-T6 cells was evaluated using ATE at 0.1 and $0.5 \mathrm{mg} / \mathrm{ml}$ concentrations measured by flow cytometer (FACSCalibur, BD Biosciences, San Jose, CA, USA) using a method reported previously ${ }^{[26]}$. For apoptosis, Annexin V-FITC and PI apoptosis detection kit I was used according to manufacturer's instructions. Data analysis was performed with CellQuest software obtained from BD Biosciences. For cell death determination, both early (Annexin $\mathrm{V}^{+}$and $\mathrm{PI}^{-}$) and late (Annexin $\mathrm{V}^{+}$and $\mathrm{PI}^{-}$) apoptotic cells were included.

\section{Quantitative Real-time polymerase chain reaction (qRT-PCR):}

The protocol for qRT-PCR was followed as described previously ${ }^{[26]}$. Briefly, total RNA was extracted from tissue samples using TRIzol Plus RNA Purification Kit (Qiagen, Valencia, $C A$, USA). From total RNA $(2 \mu \mathrm{g})$, cDNA was synthesized in a $20 \mu \mathrm{l}$ reaction using a high-capacity cDNA reverse transcription kit (Applied Biosystems, Foster, CA, USA). The internal control was $\beta$-actin and the primers used in the study was shown in Table. 1.

\section{Experimental animals:}

Specific-pathogen-free Sprague Dawley (SD) rats (6-w old, 190-210 g) of either sex obtained from a
TABLE 1: THE PRIMERS USED IN THE STUDY

\begin{tabular}{|c|c|}
\hline qRT-PCR & Primer sequences \\
\hline \multirow[t]{2}{*}{ a-SMA } & $\begin{array}{ll}\text { Forward 5'-AACACGGCATCATCACCAACT-3' } \\
\end{array}$ \\
\hline & 5'-TTTCTCCCGGTTGGCCTTA-3' \\
\hline \multirow[t]{2}{*}{ Cn type 1 a 1} & 5'-CCCAGCGGTGGTTATGACTT-3' \\
\hline & Reverse $\quad$ 5'-GCTGCGGATGTTCTCAATCTG-3' \\
\hline \multirow[t]{2}{*}{ TGF-B1 } & Forward 5'-AGGAGACGGAATACAGGGCTTT-3' \\
\hline & Reverse 5'-AGCAGGAAGGGTCGGTTCAT-3' \\
\hline \multirow[t]{2}{*}{ B-actin } & Forward 5'-CTAAGGCCAACCGTGAAAAGAT-3' \\
\hline & Reverse 5'-GACCAGAGGCATACAGGGACAA-3' \\
\hline
\end{tabular}

commercial animal breeder (Orient Bio, Seongnam, Gyeonggi-do, Korea) were used for experiments approved by the Committee of Laboratory Animals according to the Institutional Guidelines of Konkuk University, Republic of Korea (IACUC No. KU15148). The animals were housed in conventional cages under controlled conditions of temperature $\left(23 \pm 3^{\circ}\right)$, relative humidity (50 $20 \%$ ), and 12/12-h light/dark cycle with standard laboratory chow and purified water ad libitum.

\section{Experimental design:}

After one week of adaptation, a total of 50 rats were divided randomly into 5 groups consisting of 10 rats each, the normal control group, TAA group (TAA only), ATE 500 group (TAA with $500 \mathrm{mg} / \mathrm{kg}$ ATE), ATE 100 group (TAA with $100 \mathrm{mg} / \mathrm{kg}$ ), and positive control silymarin group (TAA with $50 \mathrm{mg} / \mathrm{kg}$ silymarin). Liver fibrosis was induced by intraperitoneally injecting TAA $(200 \mathrm{mg} / \mathrm{kg})$ thrice a week for $13 \mathrm{w}$ to 4 groups of rats except to the normal control group, which received normal saline ip ATE (100 or $500 \mathrm{mg} / \mathrm{kg}$ ), silymarin $(50 \mathrm{mg} / \mathrm{kg})$, or distilled water was given by gastric gavage 6 times per week starting from the $\mathrm{w} 7$ to 13 . All animals were fasted for $18 \mathrm{~h}$ after the last administration of ATE or silymarin and then blood was collected by cardiac puncture under $\mathrm{CO}_{2}$ anesthesia. For tissue analysis, liver from each rat was excised and separated as two portions. One portion of tissue was fixed in Bouin's solution for histomorphological findings and another portion of liver tissue was stored at $-80^{\circ}$ for individual fibrosis-related gene expression.

\section{Analysis of serum biomarkers (AST/ALT), GSH and hydroxyproline:}

For analysing serum biochemical parameters serum was separated using a centrifuge (3000 g, $15 \mathrm{~min}$ ) and the levels of AST and ALT were determined using a GOT-GTP assay $\mathrm{kit}^{[26]}$. Total GSH content was determined according to the method of Ellman ${ }^{[29]}$ 
and the hydroxyproline estimation was performed using a previously reported method with a slight modification $^{[30]}$. The optical density of the reaction product of GSH and hydroxyproline was read at 405 and $558 \mathrm{nM}$, respectively using a spectrophotometer (Tecan, Morrisville, NC, USA).

\section{Histopathology:}

After sacrificing the animals, the liver was quickly removed and fixed in Bouin's solution, embedded in paraffin and cut into $5 \mu \mathrm{M}$ thick sections. The tissue sections were stained with Hematoxylin and Eosin (HE) and Masson's trichrome. After regular gradient alcohol dehydration and mounting the sections were observed under a light microscope (Olympus BX-50 Microscope, Leica Microsystems, USA) and then photographed. For collagen expression analysis, the blue-stained areas in the Masson's trichrome stained sections were measured on an image analyzer (Image J, NIH, Bethesda, MD, USA).

\section{Statistical analysis:}

Data are expressed as the mean \pm standard error of the mean (SEM, $n=10)$. Statistically significant differences between groups were analyzed using one-way analysis of variance (ANOVA) followed by student's $t$-test. A value of $p<0.05$ was considered statistically significant.

\section{RESULTS AND DISCUSSION}

Liver fibrosis and treatment regimen remains a major challenge and health problem because of its complex pathogenesis causing significant morbidity and mortality. Although research to understanding the molecular consequences of liver fibrosis and its pathogenesis has been steadily growing over the last 2 decades, potential treatment for liver fibrosis is still in its infancy ${ }^{[31]}$. Traditional herbs and nutrient therapy in the management of liver diseases including fibrosis is the central component of medical practice in many parts of Asia ${ }^{[32]}$. In this study, ATE exhibited potential therapeutic benefits in ameliorating hepatofibrosis in experimental cellular and animal model.

Initially to determine the optimal concentration of ATE for in vitro evaluations, various concentrations of ATE $(0.1,0.25,0.5,1.0 \mathrm{mg} / \mathrm{ml})$ were added to Chang cells and HSC-T6 cells and cell viability was assessed using the MTT assay. ATE treatment up to $0.5 \mathrm{mg} / \mathrm{ml}$ or DMSO $(0.1 \%)$ did not exhibit any signs of cytotoxicity or altered the overall cell viability in both HSC-T6 and Chang cells (fig. 1A). Therefore, further in vitro studies were carried out using either $0.1 \mathrm{mg} / \mathrm{ml}$ and/or $0.5 \mathrm{mg} / \mathrm{ml}$ as these concentrations were considered non-toxic and pharmacologically effective.

It is well documented that deposition and qualitative changes in ECM in the liver by activated HSCs is a crucial event during liver fibrogenesis ${ }^{[33]}$. HSCs under activated state exhibit enhanced proliferation rate, contractility and collagen scar around cells with increased accumulation of ECM proteins. Thus, suppressing the effects observed in activated HSCs morphology, proliferation and collagen scar indicates attenuation of liver fibrosis ${ }^{[33]}$. In this study, the altered morphology in activated HSCs (day 7, fig.1B) was restored with ATE $(0.5 \mathrm{mg} / \mathrm{ml})$ treatment for $24 \mathrm{~h}$ (day 8) with cell degradation and decreased collagen fiber morphology (fig. 1C).

Earlier reports revealed that inhibition of HSC proliferation by blocking the cell cycle transition from G1 to S phase might aid in HSC inactivation and can prevent the progression of hepatic fibrosis ${ }^{[34,35]}$. In the activated HSC proliferation process, apoptosis is responsible for mediating HSC loss during recovery from the fibrosis and therefore, induction of HSC apoptosis might has an antifibrotic effect ${ }^{[36,37]}$. In this study, the cell cycle distribution showed marked effects in silymarin and ATE $0.5 \mathrm{mg} / \mathrm{ml}$ treated groups (fig. 2A). The percentage of cell cycle distribution revealed that treatment with $0.1 \mathrm{mg} / \mathrm{ml}$ of ATE alone did not

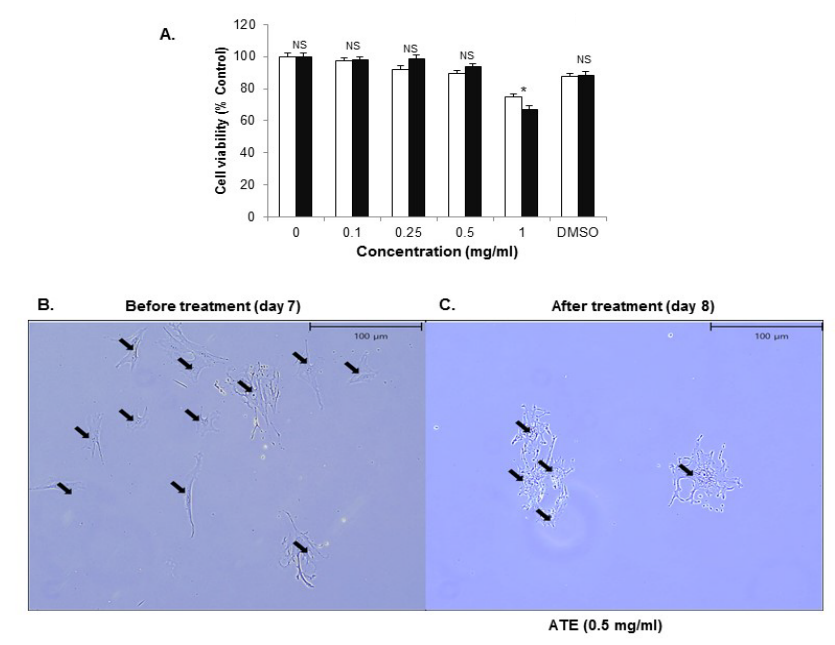

Fig. 1: Effect of ATE in cell viability assay on Chang liver/ HSC-T6 cells and morphological changes in primary HSCs

(A) Chang liver ( $\square$ ) and HSC-T6 cells ( $\square$ ) were incubated with ATE at indicated concentrations for $24 \mathrm{~h}$ and cell viability was determined by MTT assay. (B) Primary HSCs were cultivated for $1 \mathrm{w}$ and exposed to the ATE $(0.5 \mathrm{mg} / \mathrm{ml})$ for $24 \mathrm{~h}(\mathrm{C})$. Pictures were taken after $24 \mathrm{~h}$ treatment with ATE. Magnification was $100 \mathrm{X}$. Arrows indicate HSCs. The data are expressed as means \pm SEM $(n=10)$, using one-way analysis of variance (ANOVA) followed by Student's t-test. " $P<0.05$ compared to the control group, NS-not significant compared to the control group 
exhibit any alterations and was similar to untreated control group (1.08 \% for control and $1.24 \%$ for ATE $0.1 \mathrm{mg} / \mathrm{ml}$ ). However, ATE treatment at $0.5 \mathrm{mg} / \mathrm{ml}$ showed $2.58 \%$ of cells in the sub-G1 phase compared to the untreated control group. The positive control silymarin showed $3.93 \%$ of cells in the sub-G1 phase compared to the untreated group (fig. 2B).

Further, annexin V and PI double staining was performed to confirm the ability of ATE in inducing apoptosis. In Annexin V-FITC/PI assay, ATE $(0.5 \mathrm{mg} /$ $\mathrm{ml})$ and silymarin significantly $(\mathrm{p}<0.05)$ increased apoptosis in HSC-T6 cells when compared with the control group (fig. 3A-3D). In agreement with the cell cycle distribution data, ATE $0.1 \mathrm{mg} / \mathrm{ml}$ did not exhibit marked effects in inducing apoptosis. The percent of cells undergoing apoptotic cell death in control group was $12.09 \pm 2.54$, which was markedly increased to $42.12 \pm 2.74$ in the silymarin group, while it was $26.71 \pm 3.89$ in the $0.5 \mathrm{mg} / \mathrm{ml}$ ATE-treated group and $11.72 \pm 3.09$ in the $0.1 \mathrm{mg} / \mathrm{ml}$ ATE-treated group at $24 \mathrm{~h}$. When compared to the Annexin V positive cells in the control group, ATE $(0.5 \mathrm{mg} / \mathrm{ml})$ and silymarin $(0.05 \mathrm{mg} / \mathrm{ml})$ induced more than two-fold increase in Annexin V positive cells (fig. 3E). These results

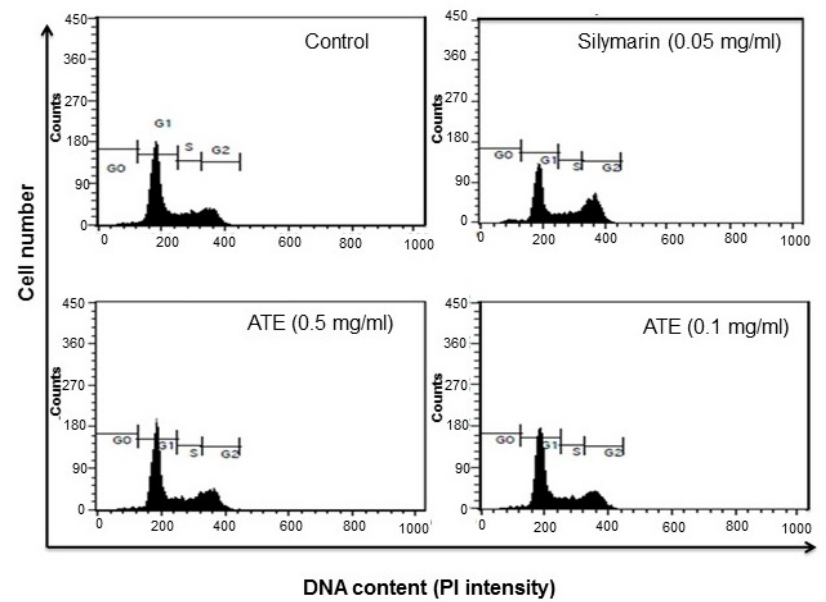

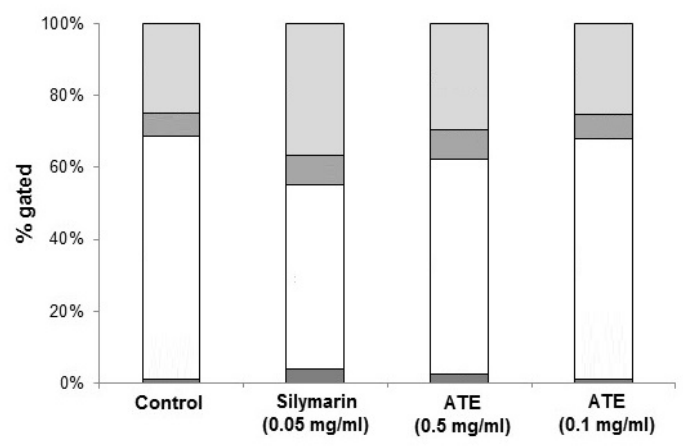

Fig. 2: Effect of ATE on the cell cycle in HSC-T6 cells

DNA content in different phases of cell cycle was measured using flow cytometry with propidium iodide. The cell cycle distribution for each treatment group and \% cell cycle distribution represented as A. graphs and B. histograms, respectively, ( () ) G2, ( $\square$ ) S, ( $\square$ ) G1 (a) G0
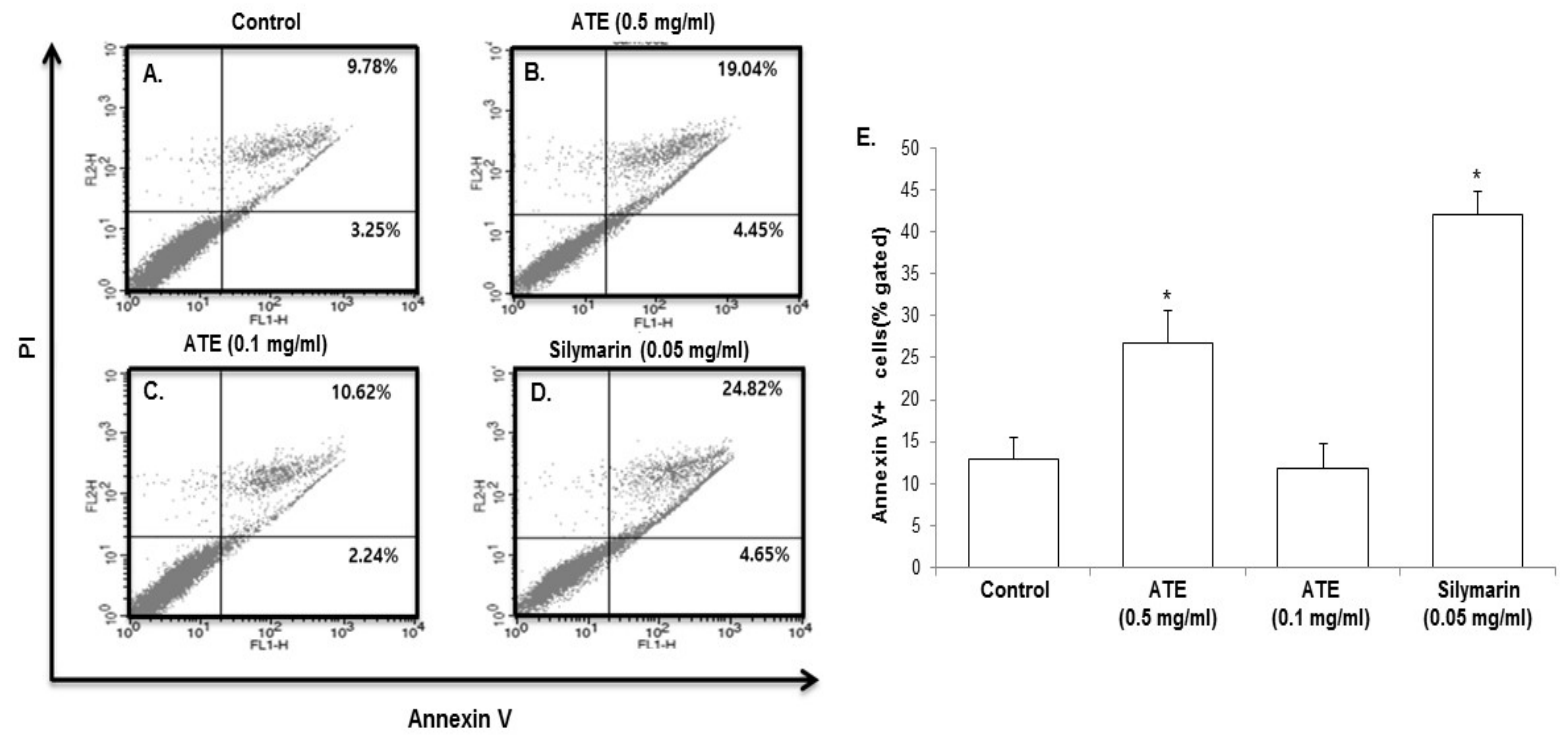

Fig. 3: Effect of ATE on apoptosis in activated HSC-T6 cells

(A) Control cells. Flow cytometry data indicate apoptosis in HSC-T6 cells after incubation with ATE (0.5 mg/ml) and silymarin 0.05 $\mathrm{mg} / \mathrm{ml}$ (B and D) for $24 \mathrm{~h}$. No effect was observed with ATE treatment at $0.1 \mathrm{mg} / \mathrm{ml}(\mathrm{C})$. Data showed the apoptotic (Annexin $\mathrm{V}^{+}$and $\mathrm{PI}^{-}$) and late apoptotic (Annexin $\mathrm{V}^{+}$and $\mathrm{PI}^{+}$) cells $(\mathrm{E})$, and represented as mean $\pm \mathrm{SEM}(\mathrm{n}=10)$ using one-way analysis of variance (ANOVA) followed by Student's t-test. " $P<0.05$ compared with control group 
suggested that ATE at $0.5 \mathrm{mg} / \mathrm{ml}$ significantly $(\mathrm{p}<0.05)$ induced cell death and apoptosis in HSC-T6 cells and also reversed the altered morphology of HSCs.

It is well known that TAA induced marked hepatotoxicity and is predominantly used to develop hepatofibrosis in several experimental studies ${ }^{[10,11]}$. In agreement with the reported data, TAA $(200 \mathrm{mg} / \mathrm{kg}$, ip) produced hepatic damage and elevated levels of ALT and AST in serum. AS shown in figs. 4A and B, TAA-induced group significantly $(\mathrm{p}<0.05)$ increased the serum levels (ALT and AST) and ATE treatment at both concentrations restored these levels significantly $(p<0.05)$. Interestingly, ATE 500 group decreased the tested serum levels to about half compared to TAAtreated group. Silymarin-treated group also showed a significant $(\mathrm{p}<0.05)$ positive trend. Further, TAA is known to produce marked hepatotoxicity in exposed animals producing excessive reactive oxygen species (ROS). The antioxidant enzyme GSH, plays an important role in protecting the cell from oxidant damage and is considered as useful marker for detection of liver function when undergoing fibrosis ${ }^{[38,39]}$. Therefore, the levels of total GSH content were examined in the serum of TAA-treated rats. As shown in fig. 4C, a significant $(p<0.05)$ decrease in GSH content was observed in TAA-treated liver tissues compared to those from the control group. However, ATE $500 \mathrm{mg} / \mathrm{k}$-treated group restored the total GSH contents to near normal levels and exhibited superior effect than positive control treated group. These data suggest that the altered antioxidant enzyme status caused by TAA was significantly ameliorated by ATE treatment.

Hydroxyproline, a major constituent of collagen is well studied as a suitable marker to correlate with ECM accumulation causing HSC proliferation and liver fibrosis ${ }^{[0-43]}$. Therefore, we evaluated the serum levels of hydroxyproline to confirm whether ATE could positively influence hydroxyproline levels in TAAinduced rats. Results indicated that the hydroxyproline levels in TAA group significantly $(p<0.05)$ increased compared to control group (fig. 4D) and ATE treatment $(100$ and $500 \mathrm{mg} / \mathrm{kg})$ significantly $(\mathrm{p}<0.05)$ attenuated this increase when compared to TAA group. Importantly, ATE $500 \mathrm{mg} / \mathrm{kg}$ and silymarin treated groupsexhibited similar effects in decreasing the hydroxyproline levels.

It is well documented that TAA treatment causes a significant change in morphological features including tissue deposition with solidified, shrunken, abnormally patterned necrosis and fibrotic scar tissues in liver ${ }^{[39]}$. HE
A.

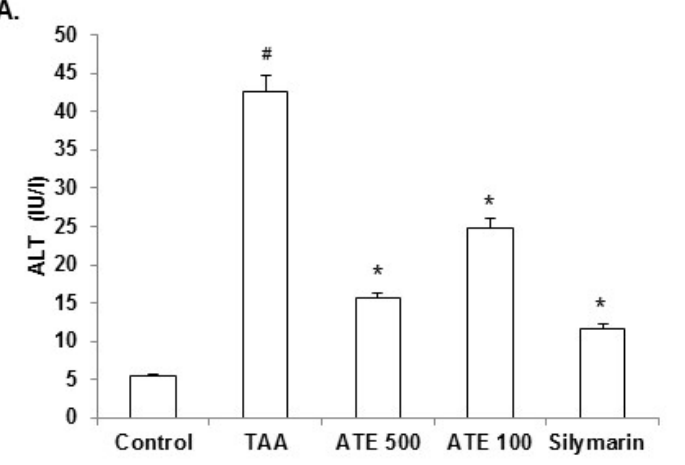

c.

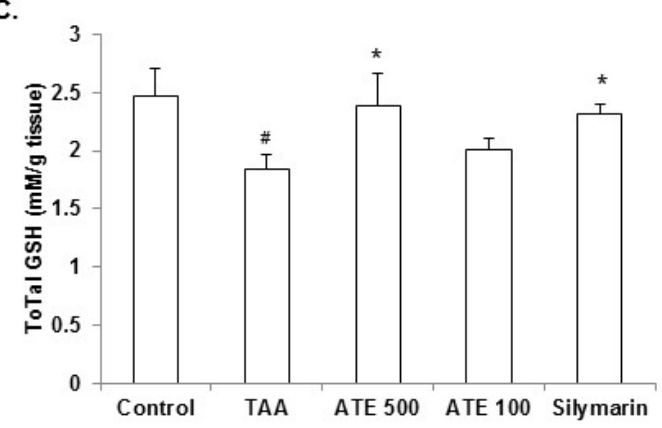

B.

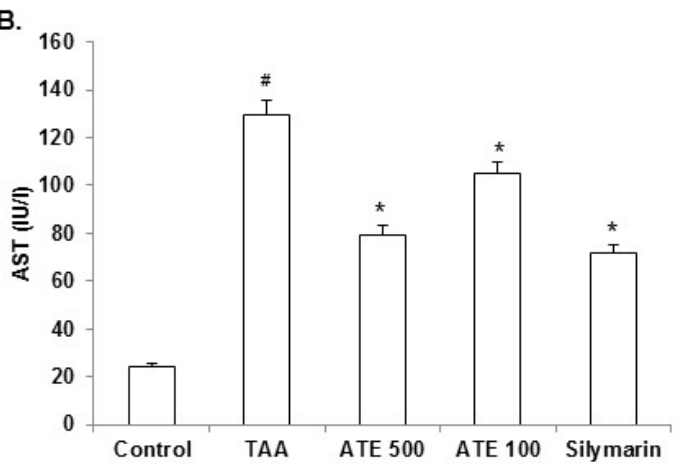

D.

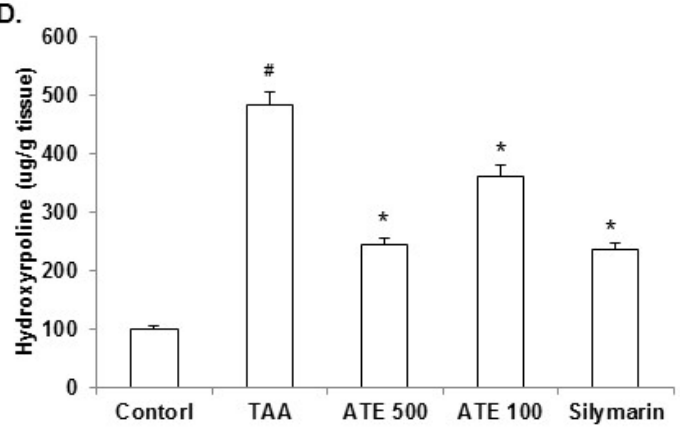

Fig. 4: Effect of ATE on serum ALT, AST, total glutathione (GSH) and hydroxyproline levels in TAA-induced rats Serum levels of (A) ALT and (B) AST, (C) total GSH and (D) hydroxyproline were measured using respective commercial kits as detailed in methods section and spectrophotometry. TAA: Thioacetamide-induced rats (200 mg/kg), Silymarin: positive control (50 $\mathrm{mg} / \mathrm{kg}$ ), ATE 100: ATE $100 \mathrm{mg} / \mathrm{kg}$ plus TAA-induced rats, ATE 500: ATE $500 \mathrm{mg} / \mathrm{kg}$ plus TAA-induced rats. The data are expressed as mean \pm SEM $(n=10)$ using one-way analysis of variance (ANOVA) followed by Student's t-test. ${ }^{\#} P<0.05$ as compared with control group and " $\mathbf{p}<0.05$ compared with TAA group 
and Massion's trichrome are the most important staining techniques used in histopathology and histochemistry for demonstration of general tissues structure as well as several intra-cellular and extra-celluar substances necessary for diagnosis of disease condition in tissues and cells $\mathrm{s}^{[44,45]}$. Therefore, whether ATE could recover the TAA-induced histomorphological changes in hepatic tissues were investigated. As shown in fig. 5A, normal morphology was observed in control rat liver tissues. However, shrunken and abnormal liver pattern with formation of regenerative nodules were observed in liver tissues from TAA-treated rats (fig. 5B). ATE 500 treatment attenuated the altered histological changes with no marked differences observed when treated with lower concentrations $(100 \mathrm{mg} / \mathrm{kg})$ of ATE (figs. $5 \mathrm{C}$ and $5 \mathrm{D})$. To further confirm the effects of ATE on TAAinduced histological changes, Massion's trichrome staining was also performed. The normal histological pattern observed in control group (fig. 6A) was altered in TAA-induced liver tissues (fig. 6B) exhibiting excessive collagen accumulation (blue stained areas). In agreement with HE staining data, ATE 500 group alone markedly decreased the collagen accumulation in the liver section with no marked effects observed at ATE $100 \mathrm{mg} / \mathrm{kg}$ dose (figs. 6C and D). Further, Silymarintreated group showed marked improvement when compared with TAA-induced group (fig. 6E). Percent area of fibrosis showed significant $(\mathrm{p}<0.05)$ damage in TAA-treated group compared to the control group (fig. $6 \mathrm{~F})$, which was restored in ATE $(100 \mathrm{mg} / \mathrm{kg}$ and 500 $\mathrm{mg} / \mathrm{kg})$-treated groups significantly $(\mathrm{p}<0.05)$.
It is well known that transforming growth factor$\beta$ (TGF- $\beta$ )- 1 is one of the main cytokines in the generation of ROS and ECM production, which can stimulate the activation and proliferation of HSC by activating its downstream Smad signaling pathway. A-Smooth muscle actin ( $\alpha$-SMA) is a marker produced in liver fibrosis which regulates essential phenomena for tissue remodeling, such as cytokine synthesis and ECM component production. Therefore, the TGF- $\beta-1 /$ Smad signaling pathway is considered a potential target for the prevention and treatment of hepatic fibrosis ${ }^{[46]}$. TGF- $\beta$ produced by Kupffer cells and HSCs, also promotes the proliferation of HSCs and strongly up regulates the transcription of the collagen- 1 and collagen-2 genes to produce a large amount of ECM, contributing to hepatocyte injury and promoting fibrosis ${ }^{[47,48]}$. In this study, TAA-treated liver showed an up-regulated TGF- $\beta$ expression while ATE-treated group $(500 \mathrm{mg} / \mathrm{kg})$ significantly $(\mathrm{p}<0.05)$ downregulated the expression (fig. 7A). Further, upregulated $\alpha$-SMA and collagen-1 alpha $1(\mathrm{Col} 1 \alpha 1)$ expression in TAA-induced groups were significantly decreased by ATE at both concentrations ( $\mathrm{p}<0.05$; figs. $7 \mathrm{~B}-7 \mathrm{C})$. The positive control silymarin also exhibited significant $(p<0.05)$ effects in down regulating the expression of selected fibrosis-associated genes. Based on these results, it could be concluded that ATE could attenuate TAA-induced liver fibrosis and this effect might be partially mediated by regulation of the TGF- $\beta 1 / \mathrm{Smad}$ signaling pathways.

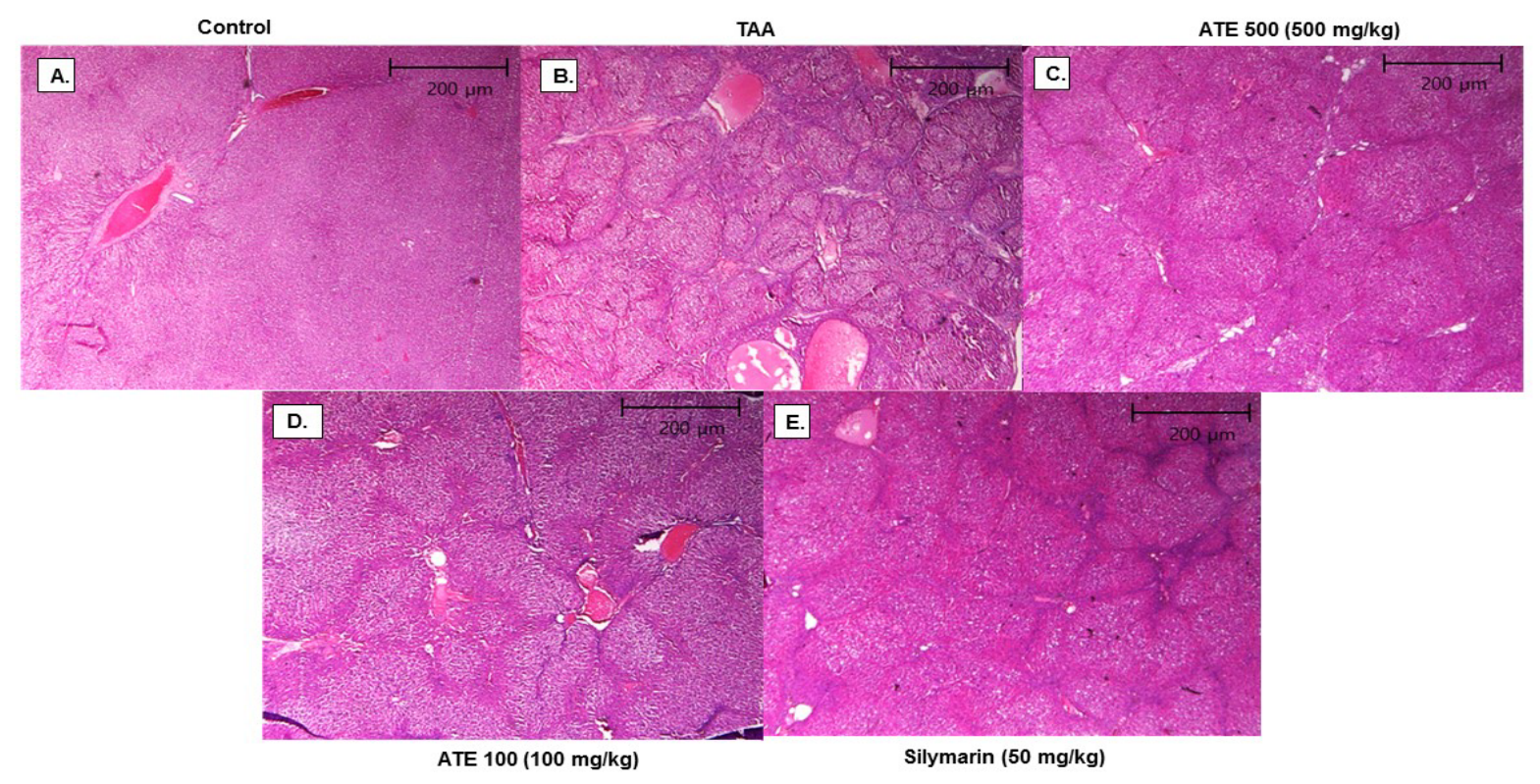

Fig. 5: Effect of ATE on histomorphology using hematoxylin and eosin (HE) stain of TAA-induced rat liver tissues Liver tissue samples fixed in Bouin's solution and sections were stained with $\mathrm{HE}$ and observed under light microscopy. (A) control rats, (B) TAA: TAA-induced (200 mg/kg) liver fibrosis rats, (C) ATE 500: ATE $500 \mathrm{mg} / \mathrm{kg}$ plus TAA-induced rats, (D) ATE 100: ATE $100 \mathrm{mg} / \mathrm{kg}$ plus TAA-induced rats, (E) silymarin $(50 \mathrm{mg} / \mathrm{kg})$ : positive control rats, scale bar $=200 \mu \mathrm{M}$ 


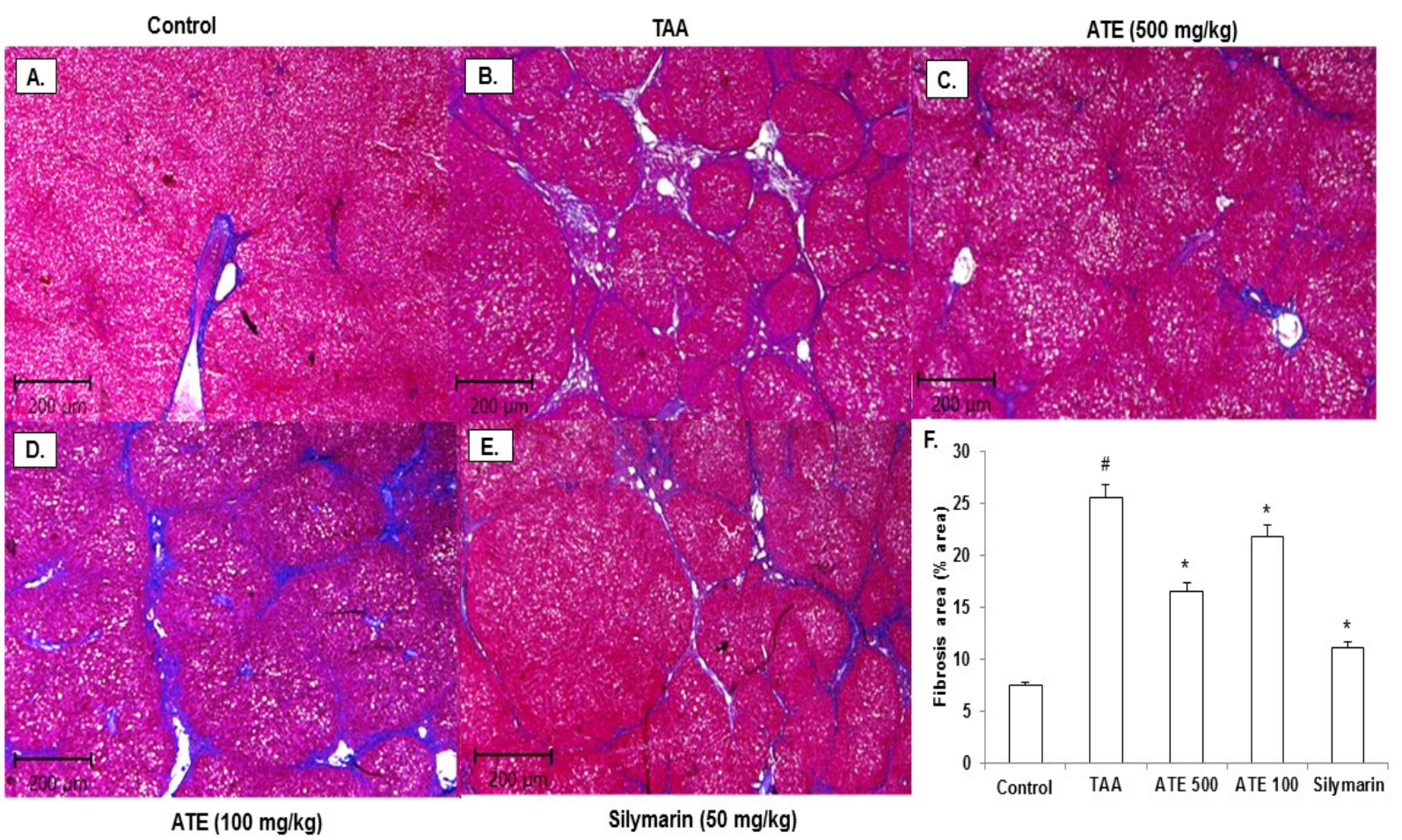

Fig. 6: Effect of ATE on TAA-induced fibrosis by Masson's trichrome stain of TAA-induced rat liver tissues

This stain was performed similar to H\&E stain. (A) control rats, (B) TAA: TAA-induced (200 mg/kg) liver fibrosis rats, (C) ATE 500: ATE $500 \mathrm{mg} / \mathrm{kg}$ plus TAA-induced rats, (D) ATE 100: ATE $100 \mathrm{mg} / \mathrm{kg}$ plus TAA-induced rats, (E) Silymarin (50 mg/kg): positive control rats, $(\mathrm{F})$ fibrosis area plot. Scale bar $=200 \mu \mathrm{M}$. Quantification was done using ImageJ. Values are represented as mean \pm SEM $(n=10)$ using one-way analysis of variance (ANOVA) followed by Student's t-test. ${ }^{*} \mathbf{P}<0.05$ as compared with control group, "p<0.05 as compared with TAA group. TAA: Thioacetamide, silymarin: positive control rats, ATE 100: ATE 100 mg/kg plus TAA-treated rats, ATE 500: ATE 500mg/kg+TAA-treated rats

A.

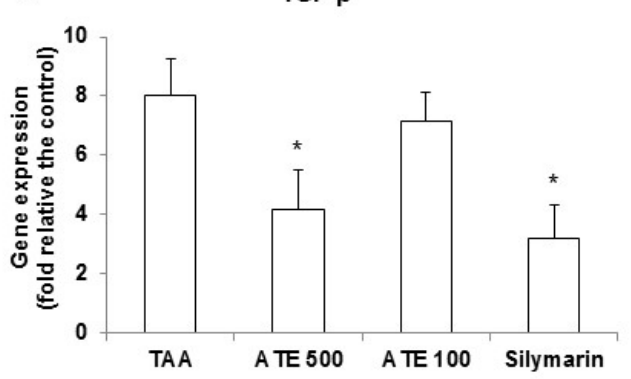

B.

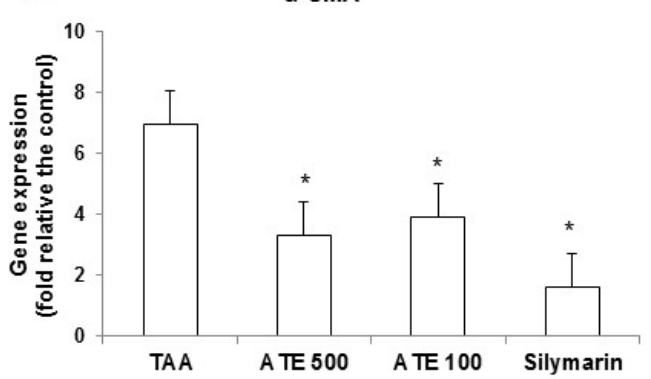

Col1a1

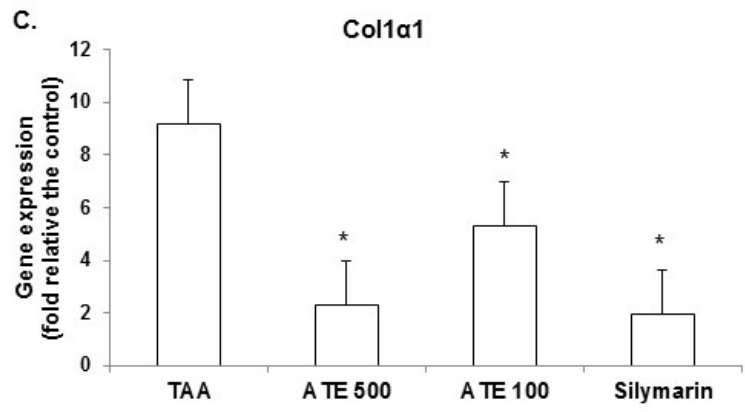

Fig. 7: Effect of ATE on TAA-induced fibrosis related gene expression in the liver tissues

Fibrosis related gene expressions of liver tissue were determined by real-time-polymerase chain reaction (RT-PCR). A: TGF- $\beta$, B: $\alpha$-SMA and C: Col1 1 . The results are expressed as normalized fold values relative to the control. Values are represented as mean \pm SEM. $(n=10)$ using one-way analysis of variance (ANOVA) followed by Student's $t$-test. "P<0.05 compared to the TAA group. TAA, Thioacetamide; ATE, A. tataricus extract; $\alpha$-SMA, alpha-smooth muscle actin; Col1 $\alpha 1$, collagen type1 alpha 1; TGF- $\beta$, transforming growth factor-beta 
Traditionally, A. tataricus is used for medicinal and several reports have indicated the presence of numerous bioactive constituents including dietary flavonoids, triterpenes, saponins and specific constituents such as epifriedelinol, caffeoylquinic acids, shionone and aster peptides shionone, epifriedelinol, quercetin, kaempferol, scopoletin, emodin, aurantiamide acetate and 1,7-dihydroxy-6-methyl-anthraquinone ${ }^{[49-52]}$. Some of these compounds, such as quercetin, saponins, kaempferol, epifriedelinol, caffeoylquinic acids possess strong antioxidant, antiinflammatory and hepatoprotective properties including antifibrotic effects $^{[33-56]}$. The compounds present in the ATE might act in a synergistic way in promoting potent antihepatofibrosis effect.

In conclusion, the present study provided scientific evidence for the traditional benefits of A. tataricus in the treatment of liver disorders. Further studies on the active constituents and exploring in-depth mechanism is quite necessary to develop A. tataricus as a potential nutrient and medicinal herb against liver fibrosis and related disorders.

\section{Acknowledgements:}

This work was supported by Konkuk University in the year 2018. The authors thankProf. Chang-Gue Son from Korean Hospital of Daejeon University, Daejeon, South Korea for generously providing immortalized rat Hepatic Stellate Cell lines.

\section{REFERENCES}

1. Henderson NC, Iredale JP. Liver fibrosis: cellular mechanisms of progression and resolution. Clin Sci 2007;112:265-80.

2. Bataller R, Brenner DA. Liver fibrosis. $J$ Clin Invest 2005;115:209-18.

3. Iredale JP, Benyon RC, Pickering J, McCullen M, Northrop $\mathrm{M}$, Pawley S, et al. Mechanisms of spontaneous resolution of rat liver fibrosis. Hepatic stellate cell apoptosis and reduced hepatic expression of metalloproteinase inhibitors. J Clin Invest 1998;102:538-49.

4. Knittel T, Kobold D, Saile B, Grundmann A, Neubauer K, Piscaglia F, et al. Rat liver myofibroblasts and hepatic stellate cells: different cell populations of the fibroblast lineage with fibrogenic potential. Gastroenterol1999;117:1205-221.

5. Friedman SL. Liver fibrosis-from bench to bedside. $\mathrm{J}$ Hepatol 2003;38:38-3.

6. Yoon C, Koppula S, Yoo S, Yum M, Kim J, Lee J, et al. Rhusjavanica Linn protects against hydrogen peroxide-induced toxicity in human Chang liver cells via attenuation of oxidative stress and apoptosis signaling. Mol Med Rep 2016;13:101925.

7. Tsukada S, Parsons CJ, Rippe RA. Mechanisms of liver fibrosis. ClinChimActa 2006;364: 33-60.

8. Li D, Friedman S. Liver fibrogenesis and the role of hepatic stellate cells: new insights and prospects for therapy. J Gastroenterol Hepatol 1999;14: 618-33.

9. Yoo SH., Yoon CJ, Kim DH, Yum MJ, Kim JS, Yoon YC, et al. Anti-fibrotic effects of Rhusjavanica Linn (Anacardiaceae) extract against Activated hepatic stellate cells via regulation of TGF-beta and smad signaling. Trop J Pharm Res 2015;14:1413419.

10. Friedman SL. Hepatic stellate cells: protean, multifunctional, and enigmatic cells of the liver. Physiol Rev 2008;88:125-72.

11. Wu J, Pan L, Jin X, Li W, Li H, Chen J, et al. The role of oxymatrine in regulating TGF- $\beta 1$ in rats with hepatic fibrosis. Acta Cir Bras 2018;33:207-15.

12. Schuppan D, Jia JD, Brinkhaus B, Hahn EG. Herbal products for liver diseases: a therapeutic challenge for the new millennium. Hepatol 1999;30:1099-104.

13. Stickel F, Schuppan D. Herbal medicine in the treatment of liver diseases. Dig Liver Dis 2007;39:293-4.

14. Zhang $\mathrm{Y}$, Wang $\mathrm{Q}$, Wang $\mathrm{T}$, Zhang $\mathrm{H}$ Tian, $\mathrm{Y}$, Luo $\mathrm{H}$, et al. Inhibition of human gastric carcinoma cell growth in vitro by a polysaccharide from Aster tataricus. Int J BiolMacromol2012;51:509-13.

15. Morita H, Nagashima S, Uchiumi Y, Kuroki O, Takeda $\mathrm{K}$, Itokawa $\mathrm{H}$. Cyclic peptides from higher plants. XVIII. Antitumor activity and hepatic microsomal biotransformation of cyclic pentapeptides, astins, from Aster tataricus. Chem Pharm Bull 1996;44:1026-32.

16. Zhang $\mathrm{Y}$, Wang Q, Wang $\mathrm{T}$, Zhang $\mathrm{H}$, Tian $\mathrm{Y}$, Luo $\mathrm{H}$, et al. Inhibition of human gastric carcinoma cell growth in vitro by a polysaccharide from Aster tataricus. Int J Biol Macromol 2012;51:509-13.

17. Zhou WB, Zeng GZ, Xu HM, He WJ, Zhang YM, Tan NH. Astershionones A-F, six new anti-HBV shionane-type triterpenes from Aster tataricus. Fitoterapia 2014;93:98-104.

18. $\mathrm{Ng} \mathrm{TB}$, Liu F, Lu Y, Cheng CHK, Wang Z. Antioxidant activity of compounds from the medicinal herb Aster tataricus. Comp BiochemPhysiol $C$ Toxicol Pharmacol 2003;136:109-15.

19. Liu X, Cao P, Zhang C, Xu X, Zhang M. Screening and analyzing potential hepatotoxic compounds in the ethanol extract of Asteris radix by HPLC/DAD/ESI-MS n technique. J Pharm Biomed Anal 2012;67:51-2.

20. Su XD, Jang HJ, Wang CY, Lee SW, Rho MC, Kim $\mathrm{YH}$, et al. Anti-inflammatory Potential of Saponins from Aster tataricus via NF- $\mathrm{KB} / \mathrm{MAPK}$ Activation. J Nat Prod. 2019; 82:1139-1148.

21. Su XD, Jang HJ, Li HX, Kim YH, Yang SY. Identification of potential inflammatory inhibitors from Aster tataricus.Bioorg Chem. 2019; 92:103208.

22. Du H, Zhang M, Yao K, Hu Z. Protective effect of Aster tataricus extract on retinal damage on the virtue of its antioxidant and anti-inflammatory effect in diabetic rat. Biomedicine \& Pharmacotherapy 2017;89:617-22.

23. Zhang HT, Tian M, He QW, Chi N, Xiu CM, Wang YB . Effect of Aster tataricus on production of inflammatory mediators in LPS stimulated rat astrocytoma cell line (C6) and THP-1 cells. Saudi Pharm J. 2017; 25: 370-5.

24. Chen Y, Dong J, Liu J, Xu W, Wei Z, Li Y, et al. Network pharmacology-based investigation of protective mechanism of Aster tataricus on lipopolysaccharide-induced acute lung injury. Int J Mol Sci. 2019; 20 pii: E543.

25. Wang R, Xiao S, Niu Z. Anti-cancer activity of Aster tataricus on SCC-9 human oral squamous carcinoma. Afr J Tradit Complement Altern Med. 2017;14:142-7.

26. Koppula S, Yum MJ, Kim JS, Shin GM, Chae YJ, Yoon T, et 
al. Anti-fibrotic effects of Orostachyus japonicus A. Berger (Crassulaceae) on hepatic stellate cells and thioacetamideinduced fibrosis in rats. Nutr Res Pract 2017;11:470-78.

27. Hendriks HFJ, Verhoofstad WAMM, Brouwer A, DeLeeuw AM, Knook DL. Perisinusoidal fat-storing cells are the main vitamin A storage sites in rat liver. Exp Cell Res 1985;160:13849.

28. Knook DL, Seffelaar AM, DeLeeuw AM. Fatstoring cells of the rat liver: their isolation and purification. Exp Cell Res 1982;139:468-71.

29. Ellman GL. Tissue sulfhydryl groups. Arch BiochemBiophys 1959;82:70-77.

30. Takayama T, Fujita K, Suzuki K, Sakaguchi M, Fujie M, Nagai $\mathrm{E}$, et al. Control of oxalate formation from L-hydroxyproline in liver mitochondria. J Am SocNephrol2003;14:939-46.

31. Benyon RC, IredaleJP. Is liver fibrosis reversible?Gut 2000;46:443-46.

32. Lee EY, Tran Thi Xuan Mai TTX, Chang Y, Ki M. Trends of liver cancer and its major risk factors in Korea. Epidemiol Health 2015;37:e2015016.

33. DeMinicis S, Seki E, Uchinami H, Kluwe J, Zhang Y, Brenner $\mathrm{DA}$, et al. Gene expression profiles during hepatic stellate cell activation in culture and in vivo. Gastroenterol 2007;132:193746.

34. Wang YQ, Ikeda K, Ikebe T, Hirakawa K, Sowa M, Nakatani $\mathrm{K}$, et al. Inhibition of hepatic stellate cell proliferation and activation by the semisynthetic analogue of fumagillin TNP-470 in rats. Hepatol2000;32:980-89.

35. Murphy FR, Issa R, Zhou X, Ratnarajah S, Nagase H, Arthur $\mathrm{MJ}$, et al. Inhibition of apoptosis of activated hepatic stellate cells by tissue inhibitor of metalloproteinase- 1 is mediated via effects on matrix metalloproteinase inhibition implications for reversibility of liver fibrosis. J Biol Chem 2002;277:11069-76.

36. Wright MC, Issa R, Smart DE, Trim N, Murray GI, Primrose $\mathrm{JN}$, et al. Gliotoxin stimulates the apoptosis of human and rat hepatic stellate cells and enhances the resolution of liver fibrosis in rats. Gastroenterol 2001;121:685-98.

37. Kawada N, Ikeda K, Seki S, Kuroki T. Expression of cyclins D1, D2 and E correlates with proliferation of rat stellate cells in culture. J Hepatol 1999;30:1057-64.

38. de Matos DG, Furnus CC, Moses DF. Glutathione synthesis during in vitro maturation of bovine oocytes: role of cumulus cells. Biol Reprod 1997;57:1420-25.

39. McClatchey KD. Clinical Laboratory Medicine. 2nd ed. Philadelphia (PA): Lippincott Wiliams \& Wilkins; 2002.

40. Reddy GK, Enwemeka CS. A simplified method for the analysis of hydroxyproline in biological tissues. ClinBiochem 1996;29:225-29.

41. Kaar JL, Li Y, Blair HC, Asche G, Koepsel RR, Huard $\mathrm{J}$, et al. Matrix metalloproteinase-1 treatment of muscle fibrosis. Acta Biomater2008;4:1411-20.
42. Aziz MA, Atta HM, Mahfouz S, Fouad HH, Roshdy NK, Ahmed $\mathrm{HH}$, et al. Therapeutic potential of bone marrowderived mesenchymal stem cells on experimental liver fibrosis. Clin Biochem 2007;40:893-99.

43. Wang Y, Gao J, Zhang D, Zhang J, Ma J, Jiang H. New insights into the antifibrotic effects of sorafenib on hepatic stellate cells and liver fibrosis. J Hepatol 2010;53:132-44.

44. Avwioro G. Histochemical uses of haematoxylin-a review. JPCS 2011;1:24-34.

45. Awvioro OG. Histochemistry and Tissue Pathology Principles and Techniques, 1st ed.; Claverianum Centre: Ibadan, Nigeria; 2002.

46. Stalnikowitz DK, Weissbrod AB. Liver fibrosis and inflammation. A review. Ann Hepatol 2003;2:159-63.

47. Jakowlew SB, Mead JE, Danielpour D, Wu J, Roberts AB, Fausto N. Transforming growth factor-beta (TGF-beta) isoforms in rat liver regeneration: messenger RNA expression and activation of latent TGF-beta. Cell Regul 1991;2:535-548.

48. Hinz B, Gabbiani G. Fibrosis: recent advances in myofibroblast biology and new therapeutic perspectives. F1000 Biol Rep 2010;2:78.

49. Yu P, Cheng S, Xiang J, Yu B, Zhang M, Zhang C, et al. Expectorant, antitussive, anti-inflammatory activities and compositional analysis of Aster tataricus. J Ethnopharmacol 2015;164:328-33.

50. Cheng D, Shao Y. Terpenoid glycosides from the roots of Aster tataricus. Phytochem 1993;35:173-76.

51. Liu F, Lu Y, Cheng CHK, Wang Z. Antioxidant activity of compounds from the medicinal herb Aster tataricus. Comp Biochem Phys C 2003;136:109-15.

52. Su XD, Jang HJ, Wang CY, Lee SW, Rho MC, Kim YH, et al. Anti-inflammatory Potential of Saponins from Aster tataricus via NF-кB/MAPK Activation. Nat Prod 2019;825:1139-48.

53. Zhang HT, Tian M, He QW, Chi N, Xiu CM, Wang YB. Effect of Aster tataricus on production of inflammatory mediators in LPS stimulated rat astrocytoma cell line (C6) and THP-1 cells. Saudi Pharm J 2017;25:370-75.

54. Wang R, Xiao S, Niu Z. Anticancer activity of Aster tataricus on SCC-9 human oral squamous carcinoma. Afr J Tradit Complement Altern Med 2017;14:142-147.

55. Hernández-Ortega LD, Alcántar-Díaz BE, Ruiz-Corro LA, Sandoval-RodriguezA, Bueno-Topete M, Armendariz-Borunda $\mathrm{J}$, et al. Quercetin improves hepatic fibrosis reducing hepatic stellate cells and regulating pro-fibrogenic/anti-fibrogenic molecules balance. J Gastroenterol Hepatol 2012;27:1865-72.

56. Zhou YP, Zhang SL, Cheng D, Li HR, Tang ZM, Xue J, et al. Preliminary exploration on anti-fibrosis effect of Kaempferol in mice with Schistosoma japonicum infection. Eur J Inflamm 2013;11:161-8. 